\title{
The influence of changing resistance on the determination accuracy of short circuits in power lines
}

\author{
Serdar Nazarov,", Gurbangulych Kelov ${ }^{1}$, and Berdimyrat Gochyev ${ }^{1}$ \\ ${ }^{1}$ State Energy Institute of Turkmenistan, st Bayramhan 62, c. Mary 745400, Turkmenistan
}

\begin{abstract}
In high-voltage electrical networks, the occurrence of short circuits leads to forced interruptions in the power supply of large consumers and disruptions in intersystem communications. More than $65 \%$ of all types of occurring short circuits are single-phase short circuits [1]. In a single-phase short circuits (SPSC), a change in the zero sequence resistance (ZSR) especially significantly affects the inaccuracy in detection of damage sites (DDS). When choosing DDS methods, preference is given to remote methods according to the parameters of the emergency conditions (PEC), which are recorded by special instruments or determined from the oscillograms of emergency conditions. The use of modern microprocessor-based relay protection and automation devices (RPA) [26] or emergency event recorders allow viewing the oscillograms of emergency events. In a branched $110 \mathrm{kV}$ network with a complex configuration, the DDS accuracy is influenced by a change in the ZSR. Averaging of specific parameters often leads to erroneous results. The choice of one value from the oscillograms puts the maintenance personnel in difficulty. In the scientific work, the influence of changes in the ZSR on the accuracy of the DDS is considered. The changes in the ZSR are influenced by the position of the on-load voltage regulator (OLTC) switches of transformers with a grounded neutral. In the work, for a more accurate record of the specific parameters of the network, a calculation program has been compiled, which allows making changes in the calculated specific parameters of the network. To determine the short-circuit current from the oscillograms, it is proposed to determine the stable state of accidents in which the current value will be approximately the same. The analysis of the oscillograms of SPSC in 110-220 kV networks in the southern part of the electric power system of Turkmenistan has been carried out.
\end{abstract}

\section{Introduction}

At present, the generating capacities of all power plants of the energy system of Turkmenistan make it fully possible to meet domestic consumption needs and increase export capacity to neighboring countries. Rapidly developing industry and growth of population in the country increase the power consumption at consumer substations. This leads to an increase in loads on substation transformers and on power lines. In the power system of the southern part of Turkmenistan, in particular, in the Mary power block, more than $4000 \mathrm{~km}$ of overhead lines with a voltage of $110-500 \mathrm{kV}$ are operated. The use of the same type (brands, crosssections, designs) of wires, switches at substations and equipping with modern devices of microprocessor relay protection and automation, as well as DDS facilitates the search for places of damage in $220-500 \mathrm{kV}$ networks. More than $50 \%$ of $110-500 \mathrm{kV}$ electrical networks in the considered part of the energy system of Turkmenistan belong to $110 \mathrm{kV}$ networks. The main settlements and enterprises built in the surrounding areas are allocated along rivers and basins. This distinctiveness affects the configuration of electrical networks. The prevalent majority of $110 \mathrm{kV}$ electrical networks in the southern part of the country have branched trunk configurations with a large number of tappings. At the same time, different branches of the electrical network are made with wires of different cross-sections and have different lengths. Branched trunk networks with tappings and a switch at the beginning of the line create some difficulties in location of damage compared to location of damage in radial electrical networks of short lengths. When choosing DDS methods, preference is given to remote methods using the parameters of emergency conditions (PEC), which are recorded by special devices or determined from the oscillograms of emergency conditions. The use of modern microprocessor-based relay protection and automation devices (RPA) [26] or emergency event recorders make it possible to view oscillograms of emergency events, as well as, when entering calculated data, allow one to independently calculate and determine the distance to damage sites. However, it is convenient in lines of the same type and structures that do not have branching and have single specific parameters. With branched lines having mixed designs, the DDS is complicated due to the impossibility of entering the specific resistivity of all sections at the same time. Averaging of specific parameters often leads to erroneous results. Determination of distances

\footnotetext{
* Corresponding author: marytdei@mail.ru
} 
according to the calculation tables of DDS is currently carried out using oscillograms of emergency modes obtained on modern relay protection and automation devices or emergency event recorders. The $110 \mathrm{kV}$ lines in the networks under consideration have one-way power supply, which forces the use of DDS methods by PEC with one-way measurements, which are one of the most economical and expedient methods.

In this work, the results of a study of the effect of resistance on the accuracy of DDS of single-phase short circuits in lines with a complex configuration are presented. Also, recommendations were developed for the selection of the emergency value from the oscillograms of emergency events.

\section{Literature review}

In the electrical network of the southern part of Turkmenistan with a voltage of $110-500 \mathrm{kV}$ has overhead lines that have been operating for over 30 years. Emergency shutdowns of overhead lines are also possible in compliance with the basic rules of structures and operations due to obsolescence of separate units and parts. The work [2] shows a graph of the growth of the failure rate of $35-220 \mathrm{kV}$ overhead lines according to the theory of probability, determined by the simplified formula of the Weibull-Gnedenko distribution with an increase in the service life. Shutdown of overhead lines often occurs for many other reasons $[3,4,5]$. In [3], the authors argue that the reasons for the shutdown of overhead lines when bypassing places of possible damage in more than $50 \%$ of cases are not revealed. In some conditions, the influence of the transient resistance [6], the resistance of the electric arc [7] in the place of the short circuit can be the cause of inaccuracy of DDS. Frequent shutdowns of overhead lines create problems for consumers and network companies. Besides, in case of unplanned shutdowns of overhead transmission lines, economic damage arises, in determining which it is necessary to take into account many factors [8]. In highvoltage electrical networks, from all types of short circuits, single-phase short circuits (SPSC) most often occur (more than 65\%) [1]. In the article [25], the authors note that the main type of damage $(70-90 \%)$ in $110-750 \mathrm{kV}$ networks is single-phase short circuits, in which it is necessary to pay attention to the transient resistance at the point of short circuit. In the article [6] the influence of the transient resistance in the place of the single phase short circuit (SPSC) of the overhead power transmission line (OPTL) is discussed. Article [7] discusses the issues of methods for calculating the resistance of an electric arc when choosing settings for distance protection (DP). The chosen approach makes it possible to build the dependences of the average resistance values, according to which a more accurate determination of the electric arc resistance is possible when calculating the DP parameters. The accuracy of determining the locations of the SPSC significantly depends on the accuracy of determining the resistance of the short-circuited circuit, which includes the zero sequence resistance.
Various DDS methods have been developed to obtain the most accurate results. The work [6] analyzes the main sources of inaccuracy in remote DDS methods. To improve the accuracy of DDS, a two-sided DDS method is proposed to refine the assessment of the damaged site based on one-sided measurements. In work [9], the results of the experimental operation of the developed complex of the wave method of DDS in a branched network with $10 \mathrm{kV}$ cable-overhead lines are presented and the application of the wave method of DDS instead of DDS method by PEC in 110-500 kV networks based on satellite synchronization of time scales and digital processing of alarm signals is given. The main advantage of the wave DDS method is its algorithmic simplicity, which does not depend on the electrical properties of the transmission line. The availability of microcontrollers with an increase in their computing capabilities allows to develop and implement software and hardware systems using the wave method of DDS in medium voltage distribution networks with different types of neutral grounding [10]. In this work [11], the author considers the wave method of two-way measurements for DDS in a line with voltage of 110 and $220 \mathrm{kV}$, which has a linear structure, i.e. does not have tappings. According to the results of the research, shows that the absolute inaccuracy with a length of the investigated line of 90 $\mathrm{km}$ is no more than $0,58 \%$. In article [12], based on the results of a study of the search for damaged sites in branched $110 \mathrm{kV}$ electrical networks with several power sources, a method is proposed for determining the damaged section of the network based on the centralized collection of emergency mode parameters. On the basis of the work carried out, the advantages of multilateral DDS were noted. In work [13], to reduce the inaccuracy, the authors propose a two-sided and multi-sided wave DDS method. In report [14], the authors propose simple practical methods for calculating DDS. At the same time, impedance and reactance methods for calculating the DDS were considered. In article [15], it is proposed to reduce the search time by improving the methods of DDS. The work presents a design diagram and methodology for use in the KATRAN-DDS software module. To obtain more accurate results, it is proposed to use the corrected specific parameters of overhead line proposed in [16]. In article [16], the authors propose the use of refined specific parameters for accurate remote DDS according to the parameters of the emergency mode of a single-phase short circuit when non-standard wires are used in $110 \mathrm{kV}$ networks. In article [17], the authors note that if the calculated parameters are incorrectly taken into account (the length of the line, the mutual influence of parallel circuits), if the asymmetry of the parameters, the nature of the grounding of the lightning protection cables along the length of the line is not taken into account, there may be methodological errors of the DDS. In work [18], the author studied DDS calculation programs for latching impulse devices (LID) used on $110-220 \mathrm{kV}$ lines of various configurations in the Buryat Republic. To increase the efficiency of DDS, the use of a method based on the measurement of zero sequence currents and voltages with a calculation program on a PC is proposed. In article [19], for lines 
with distributed parameters, a computational model was created, in which the results of DDS were studied and compared by different methods. The use of the method of two-way measurements with time synchronization is proposed. In article [20], the authors propose models with machine learning, which should be further trained and, as a consequence, predict a malfunction, and improve the accuracy of DDS. In article [21], the authors propose a simple DDS method using a computational model and a universal computation algorithm. The calculation uses the direct sequence parameters of the line and the measurement values from both ends. Computational models are created in the MATLAB program [13]. In article [27], the authors developed the principles of DDS, using vector diagrams taken from the relay protection terminals at both ends of the line. The results are confirmed on a computational model in the MATLAB / SIMULINK program.

The use of the above methods requires a two-way or multilateral measurement of the parameters of the emergency conditions and the transfer of data from the other ends. Receiving data from each node of an electrical network with a complex design will improve the accuracy of DDS. In work [28], the data transmission to telemechanic channels in $35-110 \mathrm{kV}$ networks is considered. The authors propose to increase the observability of the electrical network, which in its turn will increase the reliability of the circuit and reduce the probability of errors of dispatch personnel.

The use of digital technologies requires special attention in DDS. In article [22] the advantages of using emergency event recorders are analyzed and noted. Article [23] discusses the issues of using digital oscilloscopes data for determination of places of shorts in lines. In article [24], the authors bring the experience of increasing the accuracy of calculating the distance to the place of damage (and reducing the inspection area of overhead lines) through the use of special digital processing of signals from emergency oscillograms. Article [25] discusses the issues arising from the use of microprocessor-based latching devices, digital oscilloscopes for DDS on overhead lines 110-220 kV.

In the networks under consideration, the old (FIS-1 (latching resistance indicator), FIS-2 (Riga experimental factory "Energoavtomatika")) and modern (NEVA (Russia, St. Petersburg)) models of devices, as well as microprocessor terminals of relay protection and automation (Multilin D60, Multilin D30, Multilin L90 (USA, General Electric)), which records oscillograms of emergency shutdowns are used.

Despite to many ongoing research related to DDS, it continues to be of considerable interest. The means and methods of DDS are constantly being developed. At significant increases in the length of overhead power transmission lines, remote DDS methods are more often used.

\section{Materials and methods}

In the guidelines and scientific works for $110 \mathrm{kV}$ and above overhead lines, the influence of changes in the system resistance, transient resistance at the points of short circuit, the length of the lines, the number of grounded neutrals, loads, etc. to inaccuracy of DDS is considered. In addition, methods have been developed to take into account the influence of parallel circuits, lightning protection cables, inconsistency of wires with the dimensions of overhead lines, placement of wires on a support on separate overhead lines with one-way power supply. In the presence of tappings and the use of different cross-sections of wires on the lines, to increase the accuracy of DDS, two-sided and multilateral measurements are proposed. With complex configurations of trunk lines with the presence of the listed sections of different lengths, it leads to DDS inaccuracy according to PEC with one-sided measurements. All of the above factors, to one degree or another, affect the resistance of the short-circuited circuit and, as a result, the accuracy of DDS in trunk lines with inhomogeneous sections. There are no unified guidelines, without the use of additional devices, for such cases that increase the accuracy of DDS by PEC with one-sided measurement. Therefore, in $110 \mathrm{kV}$ trunk lines with inhomogeneous sections, it is necessary to study the effect of changes in resistance on the accuracy of DDS according to PEC of single-phase short circuits.

The investigated overhead line is shown in Figure 1 by a simplified single-line diagram with indications of the design features of separated sections. The diagram also indicates the locations of the grounded neutrals.

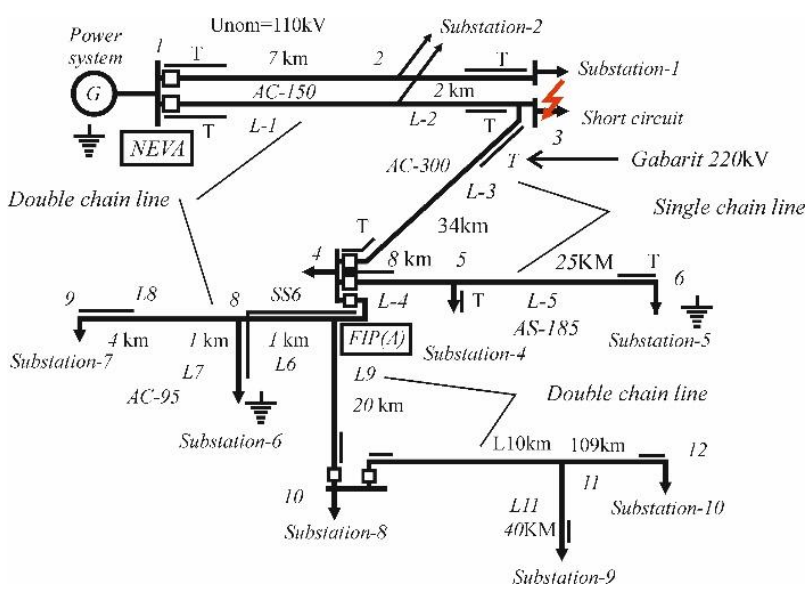

Fig. 1. Diagram of a $110 \mathrm{kV}$ electrical network with a complex configuration (ES - electric power system; Substation -1, Substation -2, Substation -3, Substation -4, Substation -5, Substation -6, Substation -7 , Substation -8 - consumer substations; L1, L2, L6, L7, L8, L9 - double-circuit $110 \mathrm{kV}$ transmission line with P110-6 and PB-110-6 supports with one lightning cable and without them in separate sections; L3 - 110 $\mathrm{kV}$ single-circuit power line with P220-3 and PB-220-1 supports with and without a lightning cable in separate sections; L4, L5 - $110 \mathrm{kV}$ single-circuit power line with P110-5 and PB-110-5 supports with or without a lightning cable in separate sections; $\mathrm{T}$ - lightning protection cable; $\mathrm{K}$ - short circuit point; 1, 2, 3, 4, 5, 6, 7, 8, 9,10 - nodes of the electrical network; GN - grounded neutral).

In the diagram in Fig. 1. lines L1, L2, L6, L7, L8 and L9 are made on double-circuit supports of types PB1106 and P110-6. L1, L2 and L9 with wires AC-150 and L6 and L8 with wires AC-95, L7 with wires AC-70. At the 
approaches of the substation, steel lightning protection cables were used (at node $1-2 \mathrm{~km}$ long, at node $3-1.5$ $\mathrm{km}$ long, from node 4 to substation -6 for the entire length of $2 \mathrm{~km}$, at the rest $1.5 \mathrm{~km}$ ). Line L3 with an operating voltage of $110 \mathrm{kV}$ (with dimensions of 220 $\mathrm{kV}$ ) is made on single-circuit supports of types PB220-1 and P220-3 with AC-300 wires and at the approaches of the substation have steel lightning protection cables (at node 2 and $4-1.5 \mathrm{~km}$ long). Lines L4 and L5 are made on single-circuit supports of types PB110-5 and P110-5 with wires AC-185 and at the approaches of the substation they have steel lightning protection cables (at nodes 4 and $6-1.5 \mathrm{~km}$ long). The neutral of the power system and transformers at substation- 5 and substation- 6 is grounded, an isolated operation mode of neutrals is possible. In the normal mode of operation of the circuit from the buses of the power system through the second circuit of lines L1, L2, L6, L7, L8, L9, L10 and L11, the second transformer T2 of substation -2 , substation -1 , substation -6 , substation -7 , substation -8 , substation 9 and substation - 10, as well as all loads of substation 3 , substation -4 and substation -5 . Nodes $2,3,5,7,8$ and 11 have tappings. The peak load at the beginning of the line reaches 110 MVA. Power supply mode from node 4 is possible. In this case, substation -6 , substation -7 , substation -8 , substation -9 and substation -10 and, if necessary, substation -4 and substation -5 are powered from node 4 , by disconnecting line L3 at node 4. In this case, DDS is determined by measurements at node 4. DDS of lines L10 and L11 is determined by measurements at node 10 .

PEC measurements are carried out on the buses of the power system in node 1 using the "NEVA" emergency event recorder, as well as in node 4 using FIP (LID) ammeters. The remote DDS method with the use of calculation tables is used. Calculation of DDS tables using averaged specific parameters and the TKZ - 3000 program leads to an increase in the DDS inaccuracy. For this, a design scheme of the network was drawn up and, with the help of calculation programs that allow, making a change in the calculated specific parameters of the network, new DDS tables were calculated taking into account the network configurations. In DDS with using emergency oscillograms, it is proposed to select the emergency current in the time interval of a stable emergency state.

\section{Discussions of results}

On the diagram of the network under consideration (Fig.1) there are sections with inappropriate dimensions, parallel circuits, single-circuit lines with and without a ground wire. And also the grounding of the neutral of the transformers is available in the power system, at substations 5 and 6 . The work proposes to use the calculation method taking into account the specified specific parameters. The greater the accuracy of accounting for specific parameters, the greater the accuracy of the OMP. For the greatest clarity of the effect of specific parameters, the graphs of the dependence $l=f(3 I 0)$ were plotted for the entire length of the line L1, L2, L3, L4 and L5.

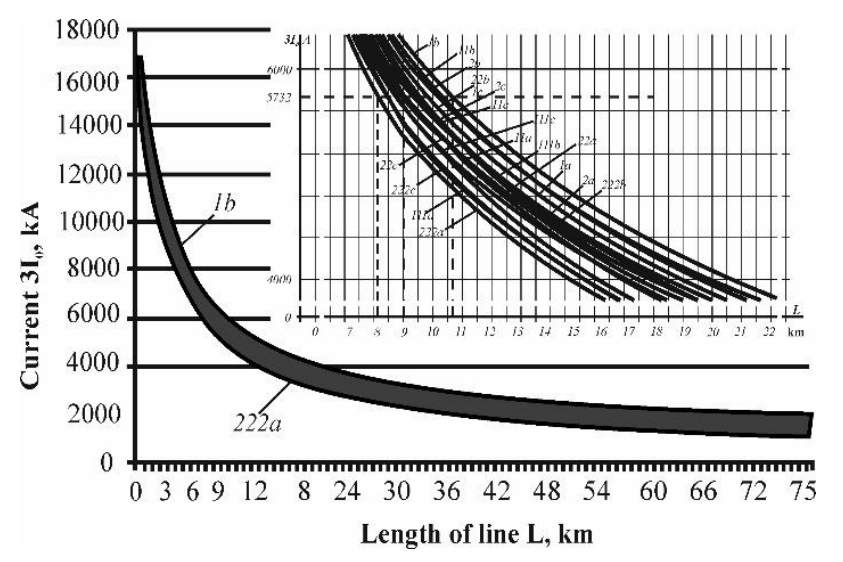

Fig. 2. Influence of the design parameters of the network on the dependence $l=f(3 I 0)$ for DDS of lines L1-L5 with disconnected L6, L9 and changing the grounding of neutrals at Substation-5 (To study the influence of the design parameters, the calculations were performed under the following conditions: - curves 1,11 and 111 - calculated only with inductive resistance, 2, 22, 222 - taking into account the total resistance; - curves 1 and 2 - calculated with the connection of two transformers at the end of the line with a grounded neutral; - curves 11 and 22 - calculated with one transformer at the end of the line, with a grounded neutral; - in curves 111 and 222 the neutral of the transformers at the end of the line are isolated; - in the family of curves with the letter a - all lines are taken without a lightning protection cable; - in the family of curves with the letter $\mathrm{b}$ - all lines are taken with a lightning protection cable; - in the family of curves with the letter c - all lines are taken with a lightning protection cable only at the approaches of the substation).

To check the calculation results and assess the level of inaccuracy, a number of SPSC oscillograms of the considered network with known fault locations were studied. When determining the places of damage according to the calculation tables or according to the calculated graphs $l=f(3 I 0)$, the dispatcher must use one value of the zero sequence current obtained from the oscillograms. In [14], the authors recommend using the values obtained in the interval from 0.75 to 1.75 of the emergency time cycle. Under the influence of aperiodic components and other factors listed in [1], the shortcircuit current in the oscillogram can be different at different times. Therefore, to determine the time interval for measuring the short-circuit current, it is proposed to determine the stable state of accidents in which the current value will be approximately the same. This interval is determined by the ratio of the emergency currents and voltages taken from the oscillograms of the emergency process according to the formulas

$$
z_{a}=\frac{U_{a}}{I_{a}} \quad \text { and } \quad z_{0}=\frac{3 U_{0}}{3 I_{0}}
$$




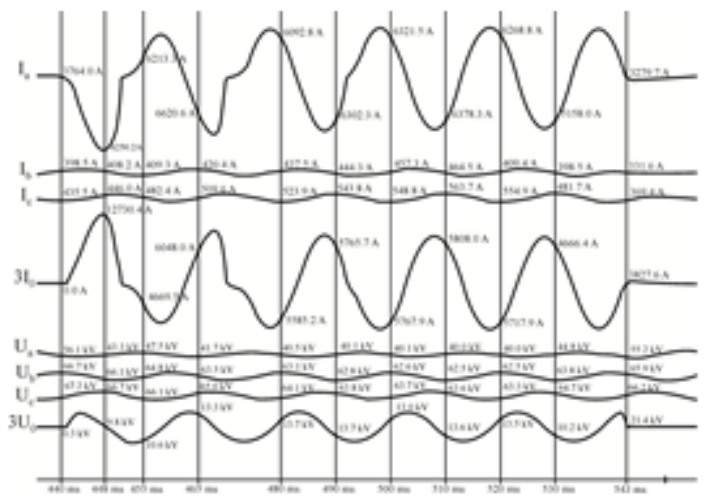

a

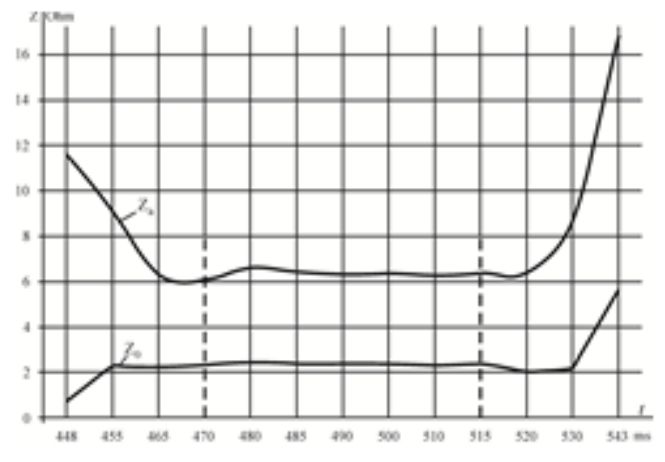

b

Fig. 3. Oscillogram of SPSC of the investigated line: a oscillogram of SPSC on the trunk line L1, L2, L3 (Fig. 1); b calculated stable period of time of the emergency process.

From the oscillogram in Fig.3.a it can be seen that the duration of the SPSC is $103 \mathrm{~ms}$. The location of the short circuit is known and is $9.0 \mathrm{~km}$ from the source. When the cursor moves, the current $3 I_{0}$ changes in a wide range (by $8 \mathrm{~ms}$ (448 ms, Fig.3.a.) from the beginning $12730.4 \mathrm{~A}$, by $90 \mathrm{~ms}$ (530 ms, Fig.3.a.) 4666.4 A). For DDS on PEC with the use of calculation tables and graphs of dependences $l=f\left(3 I_{0}\right)$, it is necessary to select preferably one current value 3I0. According to Fig.3.b, we select a relatively even interval $t_{\text {meas }}=470 \div$ $515 \mathrm{~ms}$, in which we measure the current (the average value of the current in this interval according to Fig.3.a $3 I_{0}=5731.7$ A) SPSC. According to the selected current from the graph (table), the place of the SPSC in the line is determined.

The results of DDS checking according to the graph of the dependence $l=f\left(3 I_{0}\right)$ in Fig. 2 constructed with different calculated parameters corresponding to the value of the current $3 I_{0}=5731,7 \mathrm{~A}$ (according to Fig.3.a), there is a discrepancy in the readings. The found distances can vary within $2.5 \mathrm{~km}$ depending on the change in the mode of using the neutrals of the transformers and taking into account the specific parameters. The most accurate DDS results were obtained from graphs 222.b, 11.a, 2.a, and 22.c (Fig.2). Oscillogram Fig.3. corresponds to the calculated mode of curve 22.c. When investigating accidents at other points of the network in this mode, the similarities of the results of curves 222.b, 11.a and 2.a are not observed. Close results were obtained from curves 11.a.
In connection with the installation of a new NEVA oscilloscope in node 4, the dependence graphs for the L9 line were calculated and built using the principle of plotting 22.c (Fig.2) for possible network modes. To ensure the quality of electrical energy in the trunk electrical networks, transformers with a voltage regulator switch operating under load (OLTC) are used, which change the transformation ratio on the transformers. The switches are installed on high voltage windings and by changing the number of turns they adjust the transformer ratio. Operation of the switch changes the resistance of the transformer windings. Therefore, when calculating the dependence $l=f\left(3 I_{0}\right)$, in order to reduce the inaccuarcy of the DDS, the influence of the position of the OLTC on the zero sequence resistance was investigated. For estimation in the calculations, we take the upper and lower regulation limits on transformers with an on-load tap-changer with a regulation range from - $9 \times 1.78 \%$ to $+9 \times 1.78 \%$. The calculation will be made according to the formulas [27]

$$
x_{T_{0}}^{(-9)}=[1-(0.036 \cdot(N-10))] \cdot x_{T_{0} a v}
$$

and

$$
x_{T_{0}}^{(+9)}=[1+(0.048 \cdot(10-N))] \cdot x_{T_{0} a v}
$$

where 0.036 and 0.048 are constant coefficients, $x_{T_{0} a v}$-is the zero sequence resistance of the transformer corresponding to the middle position of the OLTC.

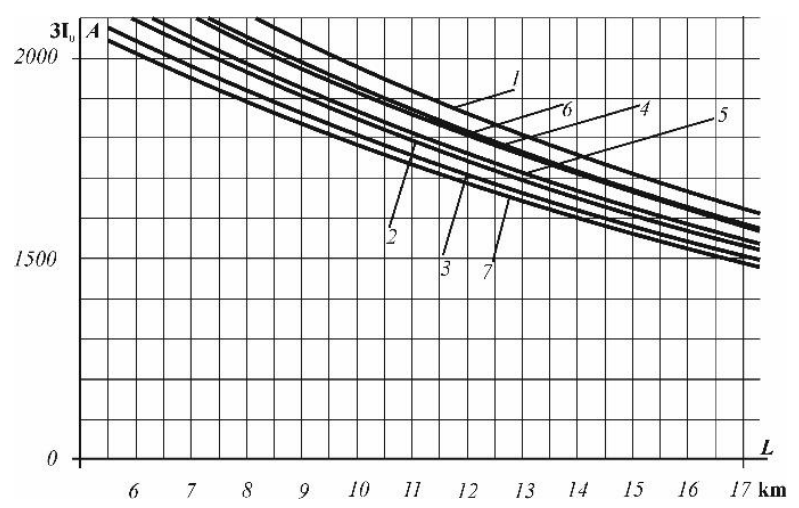

Fig. 4. Influence of OLTC on the $l=f\left(3 I_{0}\right)$ dependence for DDS of lines L9 with disconnected L10 and T1 grounded neutrals at substation - 5 and $\mathrm{T} 1$ and $\mathrm{T} 2$ at substation - 6 according to Fig.1: 1- $\mathrm{K}_{\mathrm{t}} \mathrm{min}-$ minimum transformation ratio of substation - 5 and substation - 6 transformers; 2- $\mathrm{K}_{\mathrm{t}} \max$ maximum transformation ratio of substation -5 and substation - 6 transformers; $3-\mathrm{K}_{\mathrm{t}}$ nom - nominal transformation ratio of substation - 5 and substation - 6 transformers; 4- Substation -5 $\mathrm{K}_{\mathrm{t} \text { min }}$ - the minimum transformation ratio of substation - 5 transformers at $\mathrm{K}_{\mathrm{t}}$ nom of substation - 6 transformers; 5Substation - $5 \mathrm{~K}_{\mathrm{t}} \max -$ maximum transformation ratio of substation - 5 transformers at $\mathrm{K}_{\mathrm{t}}$ nom of substation - 6 transformers; 6- Substation - $6 \mathrm{~K}_{\mathrm{t}} \mathrm{min}$ - the minimum transformation ratio of substation - 6 transformers at $\mathrm{K}_{\mathrm{t} \text { nom }}$ of substation - 5 transformers; 7- Substation - $6 \mathrm{~K}_{\mathrm{t} \max }$ - maximum transformation ratio of substation - 6 transformers at $\mathrm{K}_{\mathrm{t}}$ nom of substation - 5 transformers. 
According to the graphs of the $l=f\left(3 I_{0}\right)$ dependence (Fig.4), it can be seen that the influence of the on-load tap-changer on DDS between the upper and lower control ranges will be tangible. With a single phase short circuit current $2000 \mathrm{~A}$, a defined minimum distance will be $6.7 \mathrm{~km}$ and the maximum distance will be $9.7 \mathrm{~km}$. The DDS inaccuracy will be within $15 \%$, therefore, to reduce inaccuracy, it is proposed to study the seasonal voltage levels at the nodes of the network circuit and use correction factors.

Calculations carried out to identify the influence of the on-load tap-changer of transformers on DDS of the main line L1, L2, L3, L4 and L5 showed that with a change in the position of the switch at all adjustment ranges, it almost does not affect the curve.

\section{Conclusion}

1. In trunk power transmission lines with a complex design and unequal specific design parameters, to reduce the effect of resistance on the accuracy of DDS, it is proposed to draw up separate design diagrams for each section of the network and combine them into a common design diagram to draw up $l=f\left(3 I_{0}\right)$ dependences.

2. In the calculations, use total resistances (impedances) and for the $l=f\left(3 I_{0}\right)$ dependence determine the short-circuit current in the time interval of stable emergency resistances.

3. To reduce DDS inaccuracy from changing the position of the on-load tap-changers of transformers with grounded neutrals, it is proposed to study the seasonal voltage levels at the nodes of the main network circuit and use correction factors.

4. To minimize the effect of OLTC position changing on DDS, it is proposed to ground the neutral of the transformers in the final substation.

\section{References}

1. S.A. Ulyanov. Electromagnetic transient processes in electrical systems / M .: Energiya, 1970.

2. Mirzaabdullaev A.O. Technical diagnostics as a key factor in the reliability of overhead power transmission lines / Methodological issues of researching the reliability of large energy systems: Vol. 71. Reliability of energy supply to consumers in the context of their digitalization. In 3 books. // Book $1 / /$ Otv. ed. N.I. Shout. Irkutsk: ISEMSO RAN, 2020, 417 p.

3. Gavrish I. S. Determination of the causes of the morning emergency shutdowns of overhead power lines. [Electronic resource] / Gavrish I. S., Bankin S. A., Upit A. R. // Electric power engineering. Energy saving and energy efficiency. Renewable energy sources: a collection of articles / compiled by S.O. Khomutov [and others]. - Barnaul: LLC "MC EOR", 2018. - Access mode: http: //mceor.ru/altgtu/18006 - 01.03.2018. - Title from the screen. ISBN 978-5-6040354-2-9.
4. Borovitsky V. G. Problems of morning shutdowns of overhead power lines [Electronic resource] / V. G. Borovitsky, A. G. Ovsyannikov // Fourth Russian scientific-practical conference with international participation "Power lines 2010: design, construction, operating experience and scientific and technological progress". Novosibirsk. - Access mode: https://mzva.ru/pdf/Problemy-utrennihotkljuchenij-vozdushnyh-lini elektroperedachi.pdf.

5. I. A. Lobur, N. M. Shauleva. Analysis of the reasons for disconnection of power lines 35 and $110 \mathrm{kV}$. in the Kuzbass region [Electronic resource] // XI International Scientific and Practical Conference" Life Safety of Enterprises in Industrialized Regions". Kemerovo. Kuzbass State Technical University named after T.F. Gorbachev. November 24-25, 2015. - Access mode: http://science.kuzstu.ru/wpcontent/Events/Conference 2015/bgd2015/pages/Articles/1/30.pdf.

6. A. N. Podshivalin, G.N. Ismukov. Adaptation of methods for determining the location of damage to modern requirements for the operation of power lines / Modern trends in the development of relay protection systems and automation of power systems // Yekaterinburg, June 3 - 7, 2013 // Research Center “Bresler” LLC Russia podshivalin_a@ic-bresler.ru.

7. I. T. Titov, A.V. Bychkov, N.A. Doni. Taking into account the influence of an open electric arc on the parameters of operation of distance protection / Chuvash State University named after I.N. Ulyanova // Research and Production Enterprise "EKRA" Proceedings of NSTU named after R.E. Alekseeva number 2 (129).

8. Malkov I.S., Gribanov A.A. Assessment of economic damage from power outages. [Electronic resource] / Malkov I.S., Gribanov A.A. // Electricity. Energy saving and energy efficiency. Renewable energy sources: a collection of articles / compiled by S.O. Khomutov [and others]. - Barnaul: LLC "MC EOR", 2018. - Access mode: http: //mceor.ru/altgtu/18006 - 01.03.2018. - Title from the screen. ISBN 978-5-6040354-2-9.

9. R.G.Khuzyashev, I.L.Kuzmin, V.D.Vasiliev, S.M. Tukayev. Practical implementation of the wave method for determining the location of damage in branched distribution electrical networks $6(10) \mathrm{kV} /$ Diagnostics and monitoring p.98// Transmission and distribution. Electricity No. 2 (53) 2019.

10. R.G. Khuzyashev, I.L. Kuzmin. A method for determining the location of a single-phase earth fault in a branched overhead power line. Patent No. 2372624, 01.10.2009.

11. A. N. Smirnov. Wave method of double-sided measurements to determine the location of damage to an overhead power transmission line $110-220 \mathrm{kV}$. URL: https://www.twirpx.com/fi le / 2376241.

12. Sharygin M.V., Vukolov V.Yu., Obalin M.D., Petrov A.A. Determination of the location of damage to power lines using multilateral 
measurements / Methodological issues of researching the reliability of large power systems: Vol. 71. Reliability of energy supply to consumers in the context of their digitalization. In 3 books. // Book 2 // Otv. ed. N.I. Voropai. Irkutsk: ISEMSO RAN, 2020, 419 pp. (P. 134).

13. Dr. M.A. Baseer, Dr. Praveen R.P, Dr. A. Galal Abo Khalil, Dr. Youcef and Dr. Manaa. Localization of Fault Using Traveling Wave Theory Based on Multi-End System, International Journal of Applied Engineering Research ISSN 0973-4562 Volume 12, Number 17 (2017) pp. 6504-6513.

14. Robert Orndorff, Kyle Thomas, Patrick Hawks, Brian Starling, Amir Makki, Maria Rothweiler. Amir Makki, Maria Rothweiler. Transmission Line Fault Location Explained // 2018 Georgia Tech Fault and Disturbance Analysis Conference (2018 FDAC).

15. Panova, E.A. Method of remote location of damage in single-phase short circuits on power lines of the power supply system of an industrial enterprise. Panova, A.V. Malafeev, A.I. Pavlova // Bulletin of SUSU. Series "Energy". - 2017. - T. 17, No. 4. - P. 72-79. DOI: 10.14529 / power170408.

16. Panova E.A., Albrecht A.Ya. Refined specific electrical parameters of double-circuit $110 \mathrm{kV}$ transmission lines for remote location of damage // Electrotechnical systems and complexes. 2016. No. 4 (33). S.35-40. doi: 10.18503 / 2311-8318-2016-4 (33) -3 .

17. Misrikhanov M. Sh., Popov V.A., Medov R.V., Kostyunin D.Yu. Analysis of the methodological error in OMP on overhead lines from neglecting the phase-by-phase differences in its parameters / Increasing the efficiency of power systems: Tr. ISEU. Issue $5 / /$ Ed. V.A. Shuina, M.Sh. Misrikhanov. - M .: Energoatomizdat, 2002 .-- 520 p.

18. A.V. Korytov. Implementation of the methodology for determining the location of an earth fault by currents and voltages of zero sequence in networks of various configurations on a PC / Electric power industry through the eyes of young people: proceedings of the VI International Scientific and Technical Conference, November 9-13, 2015, Ivanovo. - B2 t. T2. - Ivanovo: FGBOUVPO "Ivanovo State Power Engineering University named after IN AND. Lenin“, 2015. - 548 p.

19. A. Gopalakrishnan, M. Kezunovic, S. M. McKenna, and D. M. Hamai. Fault Location Using the Distributed Parameter Transmission Line Model, IEEE Transactions On Power Delivery, Vol. 15, no. 4, October, 2000.

20. Baskar. D, Dr. Selvam. P. Machine Learning Framework For Power System Fault Detection and Classification, International Journal Of Scientific \& Technology Research. Vol 9, Issue 02, February, 2020.
21. Jay Prakash Keshri, Harpal Tiwari. Fault location in overhead transmission line without using line parameter, International Journal of Electrical, Electronics and Data Communication, ISSN: 23202084 Vol. 5, Issue-5, May, 2017.

22. D. N. Gura, A.L. Korolkov. Analysis of the operation of the recorders of emergency events in the operational zone of the North Caucasus Regional Dispatch Office. Proposals for its improvement / Electric power industry through the eyes of youth: proceedings of the VI international scientific and technical conference, November 9 - 13, 2015, Ivanovo. - In 2 volumes. Vol. 2. - Ivanovo: Ivanovo State Power Engineering University named after Lenin “, 2015. - 548 p.

23. S.S.A. Polushin, A.M. Chukhin. Information support for solving the problem of determining the location of a short circuit on lines of complex configuration / Increasing the efficiency of power systems: Tr. ISEU. Issue $5 / /$ Ed. V.A. Shuina, M.Sh. Misrikhanov. - M .: Energoatomizdat, 2002 .-- 520 p.

24. A. L. Kulikov, M.D. Obalin, V.A. Petrova. Increasing the accuracy of OMP power transmission lines through the use of digital processing of signals of emergency oscillograms / Electricity through the eyes of young people: proceedings of the VI International Scientific and Technical Conference, November 9-13, 2015, Ivanovo. - In 2 volumes. T 2. - Ivanovo: FGBOUVPO" Ivanovo State Power Engineering University named after IN AND. Lenin", 2015. - 548 p.

25. E.A. Arzhannikov, V.A. Mylnikov, A.M. Chukhin. Statistical estimation of the solution to the problem of determining the distance to the place of short circuit / Improving the efficiency of power systems: Tr. ISEU. Issue 5 // Ed. V.A. Shuina, M.Sh. Misrikhanov. - M .: Energoatomizdat, 2002 .-- 520 p.

26. V.N. Kozlov, Yu.V. Bychkov, K.I. Ermakov. On the accuracy of modern weapons of mass destruction // Relay protection and automation, 2016, No. 1.S. 4246.

27. Kumarraja Andanapalli, Nazeer Shaik, Srinivas Vudumudi, Bhanu Chandar Yenugu. Fault Detection, Classification and Location on Transmission Lines using Fundamental Phasor Based Approach / International Journal of Recent Technology and Engineering (IJRTE) ISSN: $2277-$ 3878, Vol.8 Issue-1S3, June 2019.

28. A.V. Malafeev, O. A. Gubina. Analysis of the sufficiency of telemetry in $35-110 \mathrm{kV}$ electrical networks according to "MES", Topical issues of energy: materials of the All-Russian. scientificpractical conf. with int. participation (Omsk, May 17, 2018) / Ministry of Education and Science of Russia, OmSTU; [editorial board: P. A. Batrakov (editor-in-chief) and others]. - Omsk: Publishing house of OmSTU, 2018. - 400 p.: ill. 